\title{
Process oriented thinking as a key for integration of ecohydrology, biotechnology and engineering for sustainable water resources management and ecosystems
}

\author{
MACIEJ ZALEWSKI \\ European Regional Centre for Ecohydrology under the auspices of UNESCO, International Institute of Polish Academy \\ of Sciences, 3 Tylna Str., 90-364 Lodz, Poland \\ mzal@biol.uni.lodz.pl
}

The recent high rate of environmental degradation due to unsustainable use of water and other natural resources and mismanagement, is, in many cases, the result of a dominant sectoral approach, limited communication between different users and agencies, and lack of knowledge transfer between different disciplines, and especially lack of dialogue between environmental scientists and engineers.

There is no doubt that the genuine improvement of human well-being has to be based on understanding the complexity of interactions between abiotic, biotic and socio-economic systems. The major drivers of biogeosphere evolution and function have been the cycles of water and nutrients in a complex array of differing climates and catchment geomorphologies.

In the face of global climate change and unequally distributed human populations, the recent sectoral mechanistic approach in natural resources management has to be replaced by an evolutionary systems approach based on well-integrated problem-solving and policy-oriented environmental science. Thus the principles of ecohydrology should be the basis for further integration of ecology, hydrology, engineering, biotechnology and other environmental sciences.

Examples from UNESCO IHP VII show how the integration of these will not only increase the efficiency of measures to harmonize ecosystem potentials with societal needs, but also significantly reduce the costs of sustainable environmental management. 